\title{
A MUlTiPliCidAdE ORIGINÁRIA: UMA LEITURA DA FILOSOFIA DE Franz RosenZWEIG
}

\author{
Oneide Perius ${ }^{1}$
}

\begin{abstract}
Resumo: O presente estudo pretende explicitar, a partir da filosofia de Franz Rosenzweig, como a tradição dominante da filosofia foi construída em torno da ideia de totalidade. O filósofo elenca uma série de consequências que se explicam com base nesse paradigma. Um novo pensamento precisa implodir essa totalidade, revelando uma multiplicidade originária que o pensamento nunca conseguiu neutralizar. $\mathrm{O}$ tempo, a experiência e o pensamento renovado são categorias centrais nessa revoluçáo filosófica proposta pelo filósofo de Kassel.
\end{abstract}

Palavras-Chave: Franz Rosenzweig. Totalidade. Multiplicidade originária. Estrela da redenção. Novo pensamento.

\section{INTRODUÇÁO}

"A fragmentação (Zerplitterung) do pensamento da totalidade estabelece, sem dúvida, o ponto central da revolução filosófica de Franz Rosenzweig", destaca Mosès (2003, p. 12). Essa afirmação de Stéphane Mosès, eminente filósofo judeu falecido em 2007, sobre a obra de Franz Rosenzweig, contém elementos muito interessantes que convergem com o que pretendemos apresentar, neste estudo. Em primeiro lugar, observa-se certa ênfase posta no termo fragmentação (Zerplitterung). Isto, certamente, é bastante compreensível. O próprio autor de A estrela da redenção evidencia isso, em uma sentença que já se tornou célebre: "Nós destroçamos o Todo. Cada uma das partes é, agora, um Todo para si." (ROSENZWEIG, F. 2002, p. 28).

Assim, a totalidade e sua fragmentação parecem mesmo ser uma das chaves, senão a chave-mestra, que pode nos levar ao núcleo do sistema

${ }^{1}$ Professor de Filosofia na Universidade Federal do Tocantins (UFT), Palmas, TO - Brasil. Doutor em Filosofia pela Pontifícia Universidade Católica do Rio Grande do Sul (PUCRS). (D) https://orcid. org/0000-0002-0298-9727 E-mail: oneidepe@yahoo.com.br.

http://dx.doi.org/10.1590/0101-3173.2020.v43n4.15.p255 
proposto pelo filósofo de Kassel. No entanto, ainda na citação de Stéphane Mosès, podemos dirigir a atenção à expressão "revolução filosófica". Qual seria exatamente essa revolução filosófica? Como essa suposta revolução se vincula, conceitualmente, com a fragmentação dessa categoria de totalidade? Quais são, nesse contexto, as novas categorias que emergem? Seria essa revolução o caminho para o novo pensamento que Franz Rosenzweig nos promete?

Esse conjunto de questôes apontadas exigiu que fizéssemos uma cuidadosa análise de algumas categorias magistralmente desenvolvidas ao longo da obra do filósofo. Propomos esta leitura, no entanto, não simplesmente para satisfazer algum desejo de elucubração filosófica. O que está em questão é a percepção de que a obra desse filósofo judeu do início do século XX, tão pouco frequentada entre nós, se impóe como uma forma extremamente lúcida e desafiadora de nos fazer perceber a importância e a centralidade de certas questôes, as quais, em plena aurora do século XXI, ainda não foram colocadas na ordem do dia.

Segundo Franz Rosenzweig (1979, p. 140), sua filosofia

[...] não pretende produzir algo como uma mera 'revolução copernicana' do pensamento, segundo a qual quem a acompanhou veja todas as coisas ao contrário, mas somente veja as mesmas coisas que já via antes. Ao invés disso, pretende uma renovaçáo total de seu próprio pensamento.

Vemos, assim, que o que se anuncia desde o início dessa obra é algo extremamente ousado e exigente. Esse novo pensamento, além de promover um profundo diálogo com a tradição filosófica e suas categorias, pretende apresentar uma realidade renovada, uma realidade outra, adequada à filosofia que reeducou seu olhar. Nesse contexto é que as categorias de totalidade e fragmentação, bem como as categorias de multiplicidade originária e novo pensamento, podem adquirir sentido.

É preciso ainda, nestas palavras introdutórias, frisar outro ponto. Franz Rosenzweig (1886-1929) escreveu a sua grande obra, ou pelo menos grande parte dela, em pleno front de batalha. Foi soldado na Primeira Grande Guerra do século passado e, ao longo dessa traumática experiência, foi dando forma a seu livro $A$ estrela da redençâo. Escrevia postais para a família com os fragmentos que viriam a compor a sua grande obra. Esse material seria publicado em 1921. O fato de a obra ter sido escrita no front, certamente, diz muito sobre sua filosofia. É uma obra que emerge do mergulho no que 
há mais brutal na ação e na tecnologia criadas pelos seres humanos: a guerra. A marca inconfundível dessa realidade se faz presente em cada palavra. No entanto, mesmo essa proximidade absoluta com o horror não a torna uma obra pessimista ou resignada. Muito pelo contrário, trata-se uma filosofia carregada de uma "urgência esperançosa." (SOUZA, 1999, p.41). A lógica da totalidade leva, no limite, à aniquilação do outro. Esta é a lógica da guerra. A realidade, em sua multiplicidade irredutível, precisa ser apresentada. A lógica da guerra não pode ser a lógica da filosofia. Resta ao filósofo mostrar, assim, o plano concreto da experiência como ponto de fuga da paranoia totalitária do pensamento.

O presente estudo, desse modo, pretende explicitar o novo pensamento de Franz Rosenzweig e as implicaçóes de se pensar uma multiplicidade originária e irredutível a qualquer programa de totalização. Pretende-se, assim, destacar a profundidade e pertinência de sua obra, no que concerne às questóes éticas e políticas com as quais o Ocidente se depara, nos anos posteriores a sua morte.

Vale ressaltar que a intenção de Franz Rosenzweig, nessa obra, como já foi frisado, é sistemática (o que é bem diferente de sistêmica). Ou seja, sua obra acompanha a constituição do conceito de totalidade como conceito central da filosofia e o movimento de reduçáo do múltiplo ao uno como característica própria desse pensamento. A multiplicidade originária será, assim, o conceito que revelará os pressupostos náo confessados do pensamento totalitário, enquanto, com sua originariedade, destrói qualquer pretensão de totalização que possa restar ao pensamento. Deus, Mundo e Homem, os três vértices do triângulo, só podem ser tematizados a partir da relação que os constitui. Nenhum desses elementos é mais antigo que o outro. $\mathrm{Na}$ origem, portanto, está a multiplicidade irredutível. Este estudo pretende apresentar esses elementos e conceitos ao mesmo tempo em que constitui o esforço de pensar suas consequências para o pensamento filosófico.

\section{O Pensamento E a totalidade}

A preocupação filosófica em fazer uma genealogia da vocação totalitária da concepção de racionalidade, que se moldou ao longo da história ocidental, não é algo novo. Especialmente depois dos totalitarismos concretos vivenciados ao longo do século XX e, mais enfaticamente, depois do extermínio sistemático de pessoas em campos de concentração, durante o século passado, essa questáo 
se impôs. A insuficiência das abordagens tradicionais, que viam o terror totalitário em pleno coração da Europa civilizada como um brusco eclipse da razão, tornou necessárias essas perspectivas distintas de análise. Um estudo mais profundo, o qual quebra a espessa camada ideológica dos discursos de legitimação da razão, põe em questão a própria razão. A suspeita é de que essa vocação totalitária seja própria da razão e não simplesmente um sintoma de sua ausência.

Assim nasce, no século XX, um movimento muito profundo que tenta revolver as bases sobre as quais está edificada a razão no ocidente. Desde a associação, na aurora da modernidade, entre saber e poder, caminha-se na direção do próprio momento inaugural da filosofia. A angústia mítica diante do desconhecido já seria, nesse caso, um índice da paranoia racional da ciência moderna, na qual tudo precisa ser identificado e conhecido. $\mathrm{O}$ conhecimento, se observarmos bem, desde a aurora da filosofia, pretende-se total, quer ser conhecimento do Todo. Desde os pré-socráticos, verifica-se a busca de um princípio que torne inteligível a totalidade. Há, dessa maneira, um vastíssimo conjunto de argumentos que podem ajudar a corroborar essa tese, nas obras dos filósofos da chamada "Escola de Frankfurt". Reagindo à exigência histórica de elucidar as razóes dos totalitarismos, esse conjunto de pensadores se pôs a perscrutar a constituição dessa racionalidade, no Ocidente. Conseguiram mostrar, a partir disso, que os totalitarismos vivenciados em pleno século XX não constituíam pontos fora da curva, mas estavam em consonância com a possível tradução política de modelos metafísicos.

Outro autor, porém, antes mesmo do ápice desses movimentos totalitários e genocidas no século XX, já se preocupava com a vocação totalitária do pensamento ocidental. Franz Rosenzweig escreveu uma obra com pretensôes sistemáticas, em 1921, intitulada $A$ estrela da redenção. Nessa obra, aborda essa questão e tenta, a partir dela, pensar uma alternativa a esse modelo. Essa proposta o autor nomeará de novo pensamento. Nessa perspectiva, pensase um conceito que é antípoda do pensamento totalitário: a multiplicidade originária. Vejamos, primeiramente, em mais detalhe, a caracterização e alcance desse conceito de totalidade.

Segundo o filósofo, é "pela morte, pelo medo da morte, que se inicia o conhecimento do Todo." (ROSENZWEIG, 2002, p.3). O medo da morte e a angústia que esse medo causa provocam a necessidade de construir um "escudo" capaz de livrar-nos de sua constante ameaça. O conhecimento do Todo promete, assim, um conhecimento pleno de todos os elementos e 
de todas as leis que o compóem. Uma vez de posse do conhecimento e da necessidade que guia o Todo, nada mais poderia nos causar angústia, pois esta é, de certa maneira, uma fraqueza e ao mesmo tempo demonstração da fragilidade humana, num ambiente incerto e ameaçador. $\mathrm{O}$ conhecimento do todo, portanto, se revela eficiente, ao realçar a "natureza" ou "essência" de cada um de seus elementos. Estes, por conseguinte, no momento em que veem seu espaço de ação delimitado por um conhecimento que lhes determina as leis de ação e composição, tornam-se presas dessa concepção de totalidade. $\mathrm{O}$ conhecimento do todo, nesse sentido, como força reativa em relação a um medo atávico da morte, realiza um fechamento da realidade, ao apontar a cada um dos elementos que a constituem uma lógica e uma necessidade próprias. Uma vez realizada essa tarefa, já não estaremos mais lidando com a realidade em sua imprevisibilidade, mas sim com uma caricatura na qual a imprevisibilidade dará lugar às certezas. Ou, então, em outras palavras, com as denominadas essências.

A realidade ou, para dizê-lo de outro modo, a estrutura fundamental da realidade que se torna legível desde esse esforço do conhecimento do todo é, dessa forma, uma realidade fechada. A antropologia pôde denominar "sociedades fechadas" aquelas sociedades que não conheciam a história, ou seja, que não entendiam a realidade como dinâmica e criadora do novo. Viam, ao invés disso, uma realidade fechada em um círculo de repetição cíclica de arquétipos intemporais. $\mathrm{O}$ mais interessante, no entanto, é o fato de que a estrutura da realidade, tal como a apresenta o conhecimento filosófico do todo, é da mesma natureza da compreensão mítica descrita. Isto é, uma vez determinada a essência de cada um dos elementos que compóem a realidade, delimita-se para cada um destes um campo de ação possível. Ele jamais poderá fazer o que não é de sua estrita natureza. A realidade se torna, assim, o palco da repetiçáo ou do eterno retorno do mesmo, para usar uma conhecida fórmula da filosofia.

Podemos ver também, de imediato, a consequência dessa visão para a crítica da filosofia. Uma filosofia que compartilha tal visão de conhecimento do todo está, ela mesma, repetindo uma visão de mundo mítica, sob uma roupagem de saber esclarecido. Com isso, vê-se que a famosa tese do livro de Theodor Adorno e Max Horkheimer, de que "do mesmo modo que os mitos já levam a cabo o esclarecimento, assim também o esclarecimento fica cada vez mais enredado, a cada passo que dá, na mitologia" (ADORNO; 
HORKHEIMER, 1980, p. 28), já é anunciada e muito bem desenvolvida na obra de Franz Rosenzweig.

Desse modo, o autor de $A$ estrela da redenção toma para si a tarefa de delinear a estrutura que assume, na história da filosofia, essa obsessão em conhecer o todo. Mais uma vez, nesse ponto, o filósofo deixa fluir sua verve polemista e anuncia como ponto de partida uma ousada tese: essa estrutura fechada da realidade, que se edifica como reação ao medo da morte, é a mesma estrutura que se repete "de Jônia até Iena” (ROSENZWEIG, 2002, p.13). Ou seja, desde os antigos filósofos pré-socráticos até a Iena de Hegel, estaria sendo compartilhada a mesma estrutura de conhecimento da realidade. Certamente, tal tese desconcertante precisa ser amplamente explicada, para que possa ser minimamente aceita. Franz Rosenzweig, porém, não se furta a essa exigência e, durante um longo trecho de seu livro, expóe e justifica essa sua tese.

Certamente, há diferenças substanciais que marcam as filosofias, ao longo desse amplo espaço de tempo compreendido entre Jônia e Iena. Franz Rosenzweig não o ignorava. Não se trata, simplesmente, de jogar fora uma tradição inteira de pensamento, em nome de uma nova visão de mundo "mais correta” que possa substituí-la. Não é essa a intenção do autor aqui analisado. Ao invés disso, o que Rosenzweig quer nos mostrar é quais são os pressupostos sistemáticos de uma filosofia que se propóe conhecer a realidade, e conhecê-la em sua totalidade. O primeiro desses pressupostos é o de que se acredita na potência do pensamento, em sua tarefa de conhecer esta realidade. $\mathrm{O}$ pensamento seria capaz de perscrutar os mais íntimos segredos e as mais profundas estruturas do que existe, conseguindo assim sistematizar, numa figura, a dinâmica do real. Por consequência, está pressuposta a anterioridade lógica do pensamento em relação à própria realidade. Isto é, o pensamento é retirado, como que por um passe de mágica, do fluxo da realidade e passa a fundar, num ato contínuo, a si mesmo e a seu outro: a realidade que quer conhecer. $\mathrm{O}$ pressuposto de que o mundo seja pensável ou inteligível (Denkbarkeit der Welt) está na raiz dessas figuras do saber do todo (ROSENZWEIG, 2002, p. 12).

A partir desse movimento argumentativo, vai-se esboçando, lentamente, um conjunto de características que podem vir a justificar a polêmica tese de nosso filósofo, de que haveria uma filosofia de "Jônia até Iena”. A característica fundamental desse conjunto de filosofias reunidas sob essa rubrica - da qual, inclusive, o pressuposto de um pensamento anterior e fundante do real não é mais do que um sintoma - é a sistemática redução da pluralidade ou 
multiplicidade ao Uno. A história da metafísica é apresentada, nesse sentido, como história desse movimento de redução da multiplicidade da realidade à unidade de um princípio hierarquicamente superior, do qual a pluralidade de manifestaçôes não seria outra coisa senão uma aparência que o pensamento, em sua potência de síntese, remeteria novamente ao "cosmos ordenado" dos princípios.

O caos da multiplicidade sempre foi o conceito-limite filosófico, no sentido de apontar para uma potência de desintegração ou desagregação. A metafísica (ou metafísicas) tinha $(\mathrm{m})$ o objetivo de ordenar o real, encontrar sua legibilidade profunda por trás do aparente "sem sentido" dos acontecimentos concretos. O caos, assim, é um conceito-limite, por ameaçar as determinaçôes e identidades estabelecidas pelo pensamento ordenador. $\mathrm{O}$ esboço de uma "figura ordenada" da realidade emerge, desse modo, como resultado das mais diversas filosofias de "Jônia até Iena". É certo que os modelos e as figuras são distintas e até mesmo - a julgar pela lógica própria de cada uma delas contrárias ou contraditórias. No entanto, Franz Rosenzweig utiliza a sutileza da análise, a fim de encontrar um movimento comum e concordante por trás das aparentes contradiçôes entre os diferentes modelos filosóficos que se perfilavam na história do Ocidente.

Três foram, em síntese, segundo o filósofo, as figuras da filosofia de "Jônia até Iena": "[...] a antiguidade cosmológica, a idade média teológica e a modernidade antropológica." (ROSENZWEIG, 1979, p.143). Como destacamos acima, o interesse de Franz Rosenzweig é sistemático, ou seja, não se trata simplesmente de propor uma visão de mundo alternativa àquelas que estâo sendo criticadas e, muito menos, opor um argumento de fundo histórico aos conceitos da tradicional filosofia. A intenção sistemática se evidencia, quando nosso autor parte da estruturação da realidade pela filosofia e, em função de seus próprios elementos e composição, desvela a lógica e os pressupostos dogmáticos que circulam no fundo desses modelos. Assim, a escolha desses diferentes elementos que, ao longo da história, serviram de fundamento ao exercício teórico de reduzir a multiplicidade do real à unidade de um princípio, não foi feita ao acaso. A própria linguagem corrente da experiência humana, no decorrer da história, nos coloca em contato com tais elementos.

No mundo grego, o princípio é o Cosmos. Essa cosmologia inclui um capítulo onde se define o espaço de atuação dos deuses e outro capítulo onde suas leis implacáveis são impostas ao homem (na figura do herói trágico, por 
exemplo), enquanto destino. A legibilidade e pensabilidade (Denkbarkeit) da realidade, nesse modelo, é garantida pela lógica do Cosmos. Mesmo a ação humana ou ação dos deuses é pensável dentro desse registro. A história, porém, segue seu curso e nela se experimentam pequenas revoluçóes que subvertem a lógica do ordenamento anterior. Emerge, no que segue, outra composição: a idade média teológica.

O curioso é que essa nova composição, mesmo alterando a posição dos termos da relação, não modifica a sua estrutura fundamental. No medievo, dessa forma, o mundo e o homem são pensáveis ou legíveis por serem "criaturas divinas". Deus assume o papel de princípio fundador da realidade. Ontologicamente, portanto, o "ser" do humano ou o que "è" o mundo são dádivas divinas. Há um único princípio que possui a potência ontológica de constituir o ser e, por conseguinte, os diferentes elementos da realidade adquirem sua inteligibilidade no conhecimento desse princípio. Dessa maneira, ainda que diferentes perspectivas se apresentem, nessa realidade, todos os elementos remetem à instância que não os deixa dispersar.

A modernidade, por sua vez, apresenta-se como ruptura profunda para com a figura do saber medieval. A perspectiva antropológica trazida pela modernidade subverte, uma vez mais, os termos dessa relação. $\mathrm{Na}$ origem estaria, de acordo com a nova figura, a consciência. O sentido do que seja o mundo ou do que seja Deus é estabelecido pela consciência do sujeito pensante. $\mathrm{O}$ princípio que unifica a pluralidade da realidade e a manifestação de seus múltiplos elementos é, assim, a consciência. No limite, essas figuras do saber moderno - já assumindo aqui o perigo que significa fazer uma síntese entre os vários modelos de filosofia, na modernidade - conduzem à ideia de Deus como projeção antropológica e a uma concepção do mundo como algo que somente existe e adquire sentido para o homem. A ideia de uma natureza totalmente esvaziada de valor e que encontraria seu sentido apenas servindo ao ser humano e seus caprichos tem, assim, uma justificação metafísica nesses modelos da filosofia moderna.

Porém, alguém poderia perguntar: mas a modernidade não é a emergência do pensamento antimetafísico por excelência? Este é outro ponto pelo qual a argumentação de Rosenzweig nos conduz para longe do entendimento fixado pelo senso comum filosófico. De acordo com filósofo, a modernidade apenas modifica, assim como foi o caso anteriormente citado da Idade Média, os termos da relação. A estrutura e, o que é mais importante, a dinâmica desse modelo de pensamento moderno repete, uma vez mais, 
a dinâmica e estrutura dos modelos anteriores. A lógica reducionista de remeter a multiplicidade do real a um princípio ontologicamente ordenador e "primeiro", em relação aos outros, é a manifestação do eterno retorno do mesmo. As mesmas estruturas se repetem e a mesma visão de mundo se repete. $\mathrm{O}$ que se modifica são os termos e os nomes, sendo que as funções relacionais dentro do sistema permanecem as mesmas. O que se modifica, apenas, é a ênfase em determinado elemento dessa relação.

É evidente, logo se percebe, que tal compreensão póe radicalmente em xeque a autocompreensão da modernidade como tempo novo (Neuzeit). A legitimação pretendida pelo discurso filosófico da modernidade, como ruptura profunda para com as figuras do saber anteriores, sempre foi uma de suas marcas fundamentais. Essa leitura é agora radicalmente posta em questáo. O tempo novo guarda, como bem o mostra Rosenzweig, um parentesco estrutural com as concepçóes que se estavam suplantando. Percebe-se também, imediatamente, em relação a essa compreensão da modernidade, a influência dessa concepção - provavelmente via Walter Benjamin - no conceito de modernidade elaborado pelo grupo de filósofos da Teoria Crítica.

No entanto, como se poderá romper com esses modelos estáticos e, ao mesmo tempo, pretensiosos de pensamento? Será possível desmentir, desde a lógica própria desses modelos, a inevitabilidade desse modo de fazer filosofia?

\section{Para além - ou aquém - da Totalidade}

Como havíamos realçado, uma consideração sistemática de nosso filósofo, em sua opus magnum, acerca dos elementos que a linguagem da filosofia articulou em modelos e sistemas, irá nos levar, a partir da potência inscrita em cada um deles, para além de qualquer sistema. Isto é, os próprios elementos que, em certo momento, foram capturados para compor uma totalidade, têm a potencialidade de explodir essa totalidade. Mostrar-se-á, assim, insuficiente qualquer perspectiva que pretenda encerrar esses elementos em uma lógica restritiva e a serviço de uma unidade fundamental do Todo.

É nesse sentido que podemos abordar a proposta de Franz Rosenzweig de uma nova filosofia. Trata-se de modificar o entendimento da lógica e da dinâmica da realidade, remetendo os elementos que a compóem à experiência sempre renovada. A palavrinha "e" (das Wörtchen Und) é o signo intransponível dessa multiplicidade constitutiva da realidade. Ao invés de uma realidade 
ordenada desde um princípio uno, uma consideração mais aguçada do mundo da experiência onde estamos desde sempre mergulhados revela a constituição plural dessa mesma realidade. Deus $e$ Mundo $e$ Homem (ROSENZWEIG, 1979, p.158). Ressalta Stéphane Mosès (2003, p. 12): "O pensamento da Totalidade, de forma paradoxal, deixa algo fora de si." Porém, como isso é possível? Para responder a essa questão, faz-se necessário reconstruir, ainda que brevemente, os primeiros movimentos argumentativos da grande obra do filósofo de Kassel.

A primeira das três partes que constituem $A$ estrela da redenção aborda os elementos, os quais, de acordo com o filósofo, são dados em qualquer experiência possível da realidade. Tendo em vista a brevidade do estudo ora empreendido, dedicaremos uma atenção especial a essa exposição inicial da obra. O título completo dessa primeira parte é, nesse sentido, bastante instigante: Die Elemente oder die immerwährende Vorwelt. Seguindo a sugestão de Ricardo Timm de Souza (1999, p. 60), traduzimos esse título da seguinte forma: Os Elementos ou o perpétuo protomundo. O que Franz Rosenzweig pretende demonstrar, nesse momento de sua obra, é a impossibilidade de, através do pensamento, mergulhar na origem. Tais elementos não podem ser reduzidos ou reconduzidos a algo mais originário em um movimento do pensamento que pudesse estabelecer sua genealogia. Ao invés disso, esses elementos são as primeiras coisas que podemos destacar do fundo obscuro do mundo (ROSENZWEIG, 2002, p. 5). De acordo com Stéphane Mosès (1985, p.56), trata-se "daquilo que é inapreensível ao pensamento. É o impensável, mas não, de todo modo, o irreal.” Dessa forma, existe uma crença como um modo de primeira manifestação do conhecimento. Ao mesmo tempo, é ela que marca o seu limite. $\mathrm{O}$ pensamento não pode penetrá-la, pode apenas pensar a partir disso.

$\mathrm{O}$ autor de $A$ estrela da redençâo, nesse sentido, abordará "elementos fáticos do todo" (ROSENZWEIG, 2002, p. 127). Esses elementos são irredutíveis uns aos outros, pois têm a mesma idade e antiguidade na linguagem. Esse modo de entender a relação desses elementos guarda uma diferença fundamental para com uma terminologia que se tornará usual na filosofia, a partir de uma obra imediatamente posterior, qual seja, Ser e tempo, de Martin Heidegger. Este, como é sabido, tratará de uma ontologia da facticidade. É importante não cair aqui na tentação de confundir essas duas filosofias pela aparente proximidade linguística de seus termos. Franz Rosenzweig jamais poderia cuidar de uma ontologia da facticidade, pois não 
há - e é isso o quer mostrar a sua obra - ser (horizonte de identidade), na raiz dessa facticidade múltipla.

A multiplicidade, no caso específico da obra do filósofo de Kassel, não é aquela, simplesmente, de um registro numérico infinito de elementos e figuras. Antes disso, é a inscrição de uma abertura fundamental e de uma potência diferidora na própria realidade de cada um desses elementos. O que está em jogo, fundamentalmente, é romper com a clausura do mundo mítico, onde a Deus se prescreve uma lógica e um espaço de ação, ao mundo se impóe uma natureza estática e arquetípica que não pode senão se repetir e, ao humano, se limita com uma essência que precisa se realizar. Ao contrário disso, segundo Rosenzweig, o mundo da experiência, no qual estamos desde sempre imersos, e de onde emergem o pensamento, a linguagem, os elementos e as açôes, é o mundo do múltiplo, o mundo sob o registro do devir e o devir inscrito em cada um de seus elementos.

O que torna impossível uma identidade estática dos elementos é o fato de eles não estarem prontos para, após isso, acidentalmente, estabelecer relaçôes. Contrariamente, as relações são a manifestação plena da realidade. Deus só se constitui como tal no ato de criação e na sempre renovada revelação ao ser humano. Não é mais, pois, um Deus mítico. O ser humano, por sua vez, rompe com sua clausura, através da abertura fundamental à revelação divina e através da ação redentora em relação ao mundo. Este, por sua vez, não será uma figura estática, mas sim aberto à ação dos seres humanos que continuam a tarefa da criação. O que Rosenzweig passa a enfatizar, dessa forma, depois da primeira parte de $A$ estrela, onde tematiza os elementos, é a sua constituição numa rede relacional. A segunda parte do livro, desse modo, com o sugestivo título Die Bahn oder die allzeiterneuerte Welt (O caminho ou o mundo sempre renovado), trata não mais dos elementos isolados, coisa que em última análise é uma abstração, porém, do conjunto de relaçôes que os constituem. Deus, Homem e Mundo são apresentados por meio das categorias relacionais da Criação, Revelação e Redenção.

Nesse momento é que a fragmentação de qualquer totalidade fica ainda mais visível. Qualquer relação só acontece no tempo e, potencialmente, marca profundamente os envolvidos. As relaçóes têm o potencial transformador de renovar a realidade, a todo o momento. O tempo passa a ser uma categoria central. A filosofia, ao pretender responder à pergunta $o$ que é? - pergunta esta que, na tradição filosófica, somente aceita como resposta uma essência que não desaparece no curso do tempo - assume a arriscada atitude de retirar 
a realidade do fluxo da vida e do tempo. A impaciência do filósofo, que não pode esperar as coisas mostrar no seu fluxo aquilo que elas são, o obriga a isolálas para, mentalmente e de forma abstrata, construir uma identidade que, na realidade, apenas se manifesta de modo difuso no tempo. A paralisia que o filósofo impóe ao seu objeto recai, no entanto, sobre a própria filosofia. O seu conhecimento não é mais um conhecimento da realidade profundamente dinâmica do fluxo da vida, mas conhecimento estático de uma totalidade pensada. A própria filosofia se petrifica. O tempo, no entanto, se levado a sério, tem o potencial de explodir qualquer totalidade, tendo em vista que nem tudo, ainda, aconteceu.

Portanto, vemos que Franz Rosenzweig demonstra o equívoco do procedimento tradicional da filosofia. Com a fina ironia que the é característica, escreve:

Toda filosofia perguntou pela "essência". É esta pergunta que a diferencia do pensamento não-filosófico do senso comum. Este não pergunta, com efeito, o que é propriamente uma coisa. Basta-lhe saber que uma cadeira é uma cadeira; e não se questiona se a cadeira seria em realidade algo totalmente diferente dela. É isso que pergunta a filosofia quando pergunta pela essência. $\mathrm{O}$ mundo não pode de modo algum ser mundo, Deus não pode de modo algum ser Deus, o ser humano de forma alguma o ser humano, mas todos têm de, "propriamente", ser algo totalmente distinto. Se não fossem algo diferente, mas apenas o que realmente são, a filosofia (Deus nos livre!) resultaria ao fim supérflua. (1979, p.143).

A filosofia de Rosenzweig, por conseguinte, não descreve instâncias ontológicas estáticas, todavia, parte de sua evidente existência na linguagem da filosofia, bem como na linguagem comum. A partir disso, constrói um sistema de filosofia narrativo, pois sua intenção não é estabelecer conceitos adequados que correspondam a cada um desses elementos, mas sim narrar a história de suas relações. Como vimos, exatamente nessas relações é que esses elementos se constituem. A categoria de experiência (Erfahrung) é o locus fundamental desse novo pensamento. A experiência do ser humano, em sua relação com o mundo, com Deus e consigo mesmo, é o ponto de partida, enquanto evidência absoluta. Ou seja, náo se trata de perguntar pela essência ou pela origem. Como vimos, permanecer em tal questão condenaria a própria filosofia. 


\section{A MULTIPLICIDADE ORIGINÁRIA}

A multiplicidade originária, desse modo - para alcançar o objetivo do presente estudo e lançar luz sobre esse conceito -, não pode ser simplesmente uma multiplicidade de funçôes que possamos continuar identificando desde nossa filosofia e de seu esforço de constituir identidades. Trata-se, como já destacamos acima, de uma multiplicidade originária e irredutível. Cada um desses elementos possui igual antiguidade e, portanto, não há genealogia ou arqueologia que consiga reduzir, uma vez mais, um ao outro. Quando começamos a pensar, tal multiplicidade originária já está atuando. E, no tempo, a multiplicidade irredutível apenas se reforça.

Mais do que, pois, uma multiplicidade identificada por um novo pensamento e uma nova filosofia, tem-se aqui uma multiplicidade constitutiva do pensamento. Nesse sentido, a própria vida do pensamento é tornada possível pela lógica diferidora dessa estrutura relacional múltipla que, por sua vez, não cessa de evidenciar como cada perspectiva - o divino, o mundano, o humano - são instâncias relacionais num perpétuo jogo de metaestabilidade. A fórmula que se poderia usar aqui como adequada é a do "eterno retorno do diferente." O mundo não está acabado. Deus não acabou de se revelar e, o ser humano, por sua vez, está constituindo sua humanidade no tempo dessas relaçóes.

Não resta, por isso, solidez ontológica no fundo desses termos. O que está em jogo aqui não é mostrar o que Deus é ou o que $o$ Mundo é ou ainda o que o ser humano é. Eles, esses elementos, nunca são outra coisa que eles mesmos. Deus é divino; o mundo é mundano; e o homem é sempre humano. A obsessão pela identidade tem, assim, um fundo tautológico. Além disso, essa obsessão pelo "ser" revela-se a marca característica de um pensamento que quer reduzir a realidade a um fundo estável e plenamente apreensível pelo pensamento, para fugir da angústia mítica ante a sombra que envolve a misteriosa origem (die dunkeln Schatten des Geheimnisses). (ROZENSWEIG, 2002, p. 291). Cada um desses elementos, no entanto, só se torna algo, quando se abre em relação aos outros elementos constitutivos da realidade. A abertura e não a clausura é, logo, a sua característica originária.

A multiplicidade originária é, dessa forma, a nova figura desse novo pensamento. Assim, se Rosenzweig continua usando o conceito de totalidade, é numa perspectiva completamente diversa daquela com que usualmente esse conceito aparecia, na filosofia. Não é uma totalidade enquanto identidade, 
mas a totalidade da perspectiva eterna do Reino onde, portanto, cada um dos elementos da realidade não cessa de, eternamente, se relacionar e se constituir, através de uma abertura constitutiva, com os outros elementos na experiência concreta do mundo da vida.

\section{Consideraçótes Finais}

Certamente, cada um dos importantes conceitos apresentados neste estudo mereceria aprofundamento. Ainda assim, como foi destacado, Franz Rosenzweig não é, entre nós, leitores brasileiros, um autor muito conhecido. Justifica-se, por conseguinte, a perspectiva mais geral e mesmo pedagógica de uma análise introdutória da obra. Isso não nos exime, no entanto, da exigência de acompanhar o desenvolvimento e de pensar as consequências desse novo pensamento, a partir das categorias que consideramos centrais para a realizaçáo desta tarefa, em especial a categoria da multiplicidade originária. Desse modo, pretendemos ter conduzido a argumentação de forma suficientemente clara para que o núcleo dessa nova filosofia tenha se tornado legível. Como vimos, não se trata de um novo pensamento, o qual, uma vez mais, se propóe articular novos conceitos e uma nova visão de mundo. Ao invés disso, Franz Rosenzweig leva a sério a exigência ética de renovar o pensamento, quando a própria realidade o exige. A multiplicidade real implode os conceitos que pretendiam tê-la eliminado. Ou seja, quando os grandes sistemas pretendiam ter dissolvido os enigmas e explicado a realidade, o filósofo de Kassel indica que a realidade não é, simplesmente. Muito pelo contrário, a realidade continua sendo. $\mathrm{Na}$ origem, está o verbo e não o ser, a relação e não a identidade.

Entretanto, se Rosenzweig não é um filósofo ainda muito conhecido entre nós, isso não é o caso, quando acompanhamos o amplo desenvolvimento da filosofia no século XX. Autores de peso, como Walter Benjamin, Jacques Derrida e Emmanuel Levinas, para citar alguns de maior destaque, perceberam imediatamente a potencialidade e a importância de sua obra. Até mesmo o amplo desenvolvimento das chamadas filosofias da diferença - embora, em muitos casos, não tenham relação direta com o pensador aqui apresentado nos mostra como, já na aurora do século XX, esse instigante pensador colocava para si questôes que seriam decisivas e marcariam profundamente todo o pensamento filosófico do século XX.

O presente estudo, dessa forma, é um convite à leitura. Mas não simplesmente pelo fato de ser mais um pensador com uma visão de 
mundo diferente, entre as quais poderíamos escolher no amplo mercado contemporâneo das ideias. O convite à leitura da obra de Franz Rosenzweig se dá por outro motivo. Percebe-se que, em sua obra, são apontadas questôes que a filosofia, de forma geral, ainda não levou suficientemente a sério. Mesmo agora, na aurora do século XXI, a tradição filosófica em que o autor se inscreve continua sendo uma tradição marginal. Mesmo assim, desde essas margens da filosofia ecoam vozes potentes que soam como desafios ao pensamento, ainda que em muitos casos os ouvidos ainda não estejam educados para escutá-las.

PERIUS, O. The original multiplicity: a reading of Franz Rosenzweig's philosophy. Trans/form/ açāo, Marília, v. 43, n. 4, p. 255-270, Out./Dez., 2020.

\begin{abstract}
The present study intends to explain, from the philosophy of Franz Rosenzweig, how the dominant tradition of philosophy was built around the idea of totality. The philosopher shows a series of consequences that are explained from this paradigm. A new thought has to implode this totality and revealing an original multiplicity that thought has never been able to neutralize. Time, experience and renewed thought are central categories in this philosophical revolution proposed by the philosopher of Kassel.
\end{abstract}

Keywords: Franz Rosenzweig. Totality. Original multiplicity. Star of Redemption. New thought.

\title{
REFERÊNCIAS
}

ADORNO, T. W; HORKHEIMER, M. Dialektik der Aufklärung: philosophische Fragmente. In: ADORNO, T. W; HORKHEIMER, M. Gesammelte Schriften in 20 Bänden. (Herausgegeben von Rolf Tiedemann unter Mitwirkung von Gretel Adorno). Frankfurt am Main: Suhrkamp, 1980.

MOSÈS, S. System und Offenbarung. Die Philosophie Franz Rosenzweigs. München: Wilhelm Fink Verlag, 1985.

MOSÈS, S. Vorwort. In: SCHWARTZ, Michal. Metapher und Offenbarung: Zur Sprache Franz Rosenzweigs Stern der Erlösung. Frankfurt am Main: Nexus Druck, 2003.

ROSENZWEIG, F. Das neue Denken: Einige nachträgliche Bemerkungen zum “Stern der Erlösung.” In: ROSENZWEIG, F. Gesammelte Schriften, Band 3: Zweistromland. Kleinere Schriften zu Glauben und Denken. (Herausgegeben von Reinhold und Annemarie Mayer). Den Haag, 1979. 
PERIUS, O.

ROSENZWEIG, F. Der Stern der Erlösung. Freiburg: Universitätsbibliothek, 2002.

SOUZA, R. T. de. Existência em Decisáo: uma introduçáo ao pensamento de Franz Rosenzweig. Sáo Paulo: Perspectiva, 1999.

Recebido: 07/6/2018

Aceito: 29/06/2019 